\title{
Desenvolvimento de Software Educacional para Representação e Reconhecimento de Som Aplicado à Ausculta Cardiovascular
}

\author{
Bruno Carlos da C. Costa ${ }^{1}$, Leandro Segheto Moraes ${ }^{2}$, Júlio César da Silva ${ }^{3}$, \\ Elisabete do Rêgo Lins ${ }^{4}$, Marco Antônio Freire Allemão ${ }^{5}$ e Wolney de Andrade \\ Martins $^{6}$ \\ ${ }^{1}$ UNIFESO, CCT, Ciência da Computação, brunocosta.dsn@gmail.com \\ ${ }^{2}$ UNIFESO, CCT, Ciência da Computação, leandrosegheto@yahoo.com.br \\ ${ }^{3}$ UnIfESo, CCT, Ciência da Computação e PUC-Rio, Departamento de \\ Engenharia Civil, jcesaropegmail.com \\ ${ }^{4}$ UNIFESO, CCT, Ciência da Computação, betelins@terra.com.br \\ ${ }^{5}$ UNIFESO, CCT, Ciência da Computação, allemao@uol.com.br \\ ${ }^{6}$ UNIFESO, CCM, Medicina, wolney_martins@yahoo.com.br
}

\begin{abstract}
Resumo. No ensino da medicina, especificamente, em laboratórios de estudos e práticas, existe uma preocupação de resguardar o máximo o paciente, buscando o mínimo de constrangimento, porém sem deixar que o aprendizado seja prejudicado. Com o objetivo de capacitar o discente para a prática em ausculta cardiovascular, sem que o contato com o paciente seja necessário, foi desenvolvido o sistema CARDIOS. Contendo informações de doenças cardiovasculares, o aluno conhece o som e o respectivo registro gráfico. A utilização de aparelhos específicos, como um estetoscópio eletrônico, promove a visualização e amplificação do som em tempo real. $O$ uso de agentes inteligentes possibilita o reconhecimento do som cardíaco, classificando-o em normal ou patológico.
\end{abstract}

\section{Introdução}

Atualmente, o uso indiscriminado da tecnologia por especialistas pode ser tratado como um problema, pois o avanço das tecnologias na medicina acaba tornando o especialista quase totalmente dependente delas para o diagnóstico. Por isso, todo médico, especificamente o cardiologista, deve ser capaz de levantar um diagnóstico inicial através de um simples exame físico, a ausculta cardíaca, porém, isto não vem acontecendo. Principalmente entre os especialistas recém formados, há uma perda desta sensibilidade, o que é prejudicial para toda a área médica. Como a maioria dos casos resulta em um pedido de um exame mais detalhado, o Eletrocardiograma, por exemplo, se torna mais fácil este pedido logo num primeiro momento a analisar cuidadosamente $o$ som ou ruído gerado pelo batimento cardíaco.

A motivação deste trabalho está no fato do software ser utilizado para auxiliar, no ensino para a identificação de doenças e suas respectivas características. Tornando mais precisa a decisão sobre a necessidade de realização de um exame mais detalhado. O registro gráfico apresentado juntamente com o som, é chamado de Fonocardiograma, não sendo mais utilizado expressivamente para o diagnóstico, pois foi substituído por exames mais avançados, como o Ecocardiograma. Porém, isto não justifica o completo desconhecimento, por parte do especialista, do registro sonoro e diagnóstico, ao menos inicial, tendo por base a análise do som ou ruído cardiovascular. 


\section{Revista TECCEN - Edição Especial - volume 2 - número 1 - março de 2009 - ISSN 1984-0993}

O objetivo deste trabalho é a reprodução do som dos batimentos cardíacos, representa gráfica e reconhecimento do mesmo, promovendo a classificação dos sons auscultados como normal ou patológico.

\section{Características e representação do som}

\subsection{Definição de som}

O som é o resultado de um movimento vibratório da matéria transmitido através de um meio. É energia que se propaga através de ondas, chamadas de ondas mecânicas, pois precisam de um meio material para se propagar. Este meio pode ser sólido, como a terra; líquido, como a água; ou gasoso, como o ar [Hewitt 2002].

\subsection{Captação e conversão do som}

Para tornar-se digital, é necessário que o som seja captado. A captação do som é feita por equipamentos que contém um conversor Analógico/Digital, ou AD. Tais aparelhos são capazes de converter um som totalmente analógico (voltagem) em números (bits). Por exemplo, o microfone.

Conforme citado, quando o som é captado ele é enviado para um conversor $\mathrm{AD}$, através de um microfone. O sinal elétrico será digitalizado, convertido em informações expressas em números, e armazenado em um meio digital. Para a reprodução existe um respectivo conversor DA (Digital/Analógico). O AD precisa transformar voltagens em números. O DA faz o contrário, recriando o som analógico depois de ele ter sido processado pelo computador para que o alto-falante possa reproduzir o resultado (Figura $1)$.

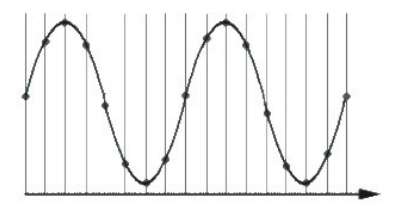

Figura 1. Reconstituição do som analógico pelo conversor AD.

\subsection{Processo de digitalização}

Milhares de vezes por segundo, o conversor AD "anota" o estágio da oscilação e lhe atribui um valor numérico, por exemplo, 44.100 vezes por segundo, resultando em uma taxa de amostragem de $44.1 \mathrm{kHz}$. A cada amostragem, o conversor mede a amplitude e codifica-o em um valor numérico. Essa forma de medir o sinal é chamada de Amostragem ("sampling"), e a conversão da amplitude em valor numérico é chamada de quantização ("quantize"). As duas compõem o processo de digitalização (Figura 2).

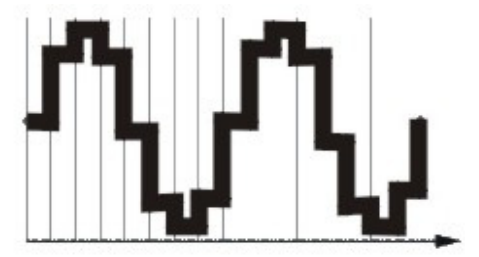

Figura 2. Espectro da onda sonora depois de digitalizada. 

ISSN 1984-0993

\subsection{Representação do som}

O som, sendo ondas produzidas por vibrações de objetos materiais. Em cada um desses casos, a vibração original estimula a vibração de algo maior e mais massivo, como uma caixa de ressonância de um instrumento de corda. Este material vibrante, então, envia uma perturbação através do meio circulante, por exemplo, o ar, em forma de ondas longitudinais. Uma onda longitudinal ocorre quando as partes que constituem o meio são movidas para frente e para trás na mesma direção em que se propaga a onda [Hewitt 2002]. O comportamento de uma onda longitudinal pode ser demonstrado com uma mola comprida, presa em uma das extremidades a uma parede. Fazendo o movimento de empurrar e puxar rápido e repetidamente, partes da mola estão comprimidas, e uma onda de compressão percorre a mola. Entre as regiões de compressão, existe uma região onde a mola está distendida, chamada de rarefação. Tanto a compressão como a rarefação se propagam na mesma direção, ao longo da mola. As ondas de som são ondas longitudinais (Figura 3).

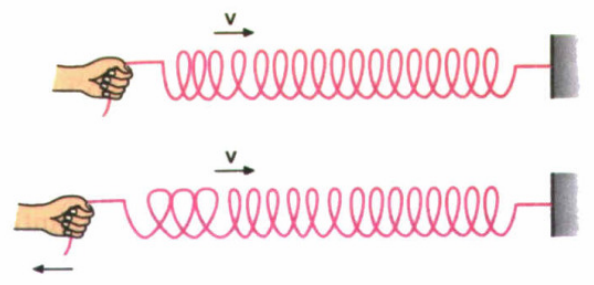

Figura 3. Demonstração de uma mola longitudinal com uma mola.

\subsection{Compressão e rarefação}

Considere um diapasão próximo a um tubo, conforme a Figura 4.

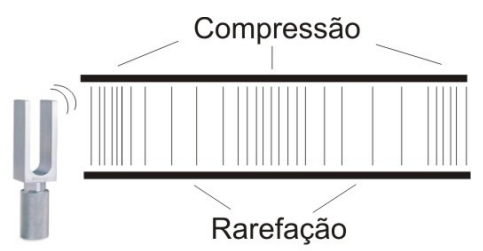

Figura 4. Som se propagando a partir da vibração de um diapasão.

Quando o ramo direito do diapasão se move em direção ao tubo, ele empurra as moléculas de ar mais próximas a ele em direção ao tubo num pulso de ar comprimido, este pulso é chamado de compressão. Quando este ramo balança em sentido contrário, afastando-se do tubo, ele empurra algumas moléculas para fora, produzindo uma área de baixa pressão próxima ao ramo, conseqüentemente as moléculas adjacentes são movidas para esta zona, deixando para trás uma zona com ar rarefeito, a esta perturbação dá-se nome de rarefação.

Em 1822, um matemático francês Joseph Fourier descobriu que este movimento pode ser decomposto em simples ondas senoidais que se adicionam [Fourier 2008]. Ondas senoidais são aquelas com a forma de uma função seno ou cosseno, é a mais simples de todas as ondas, possuindo uma única freqüência, conforme a Figura 5.

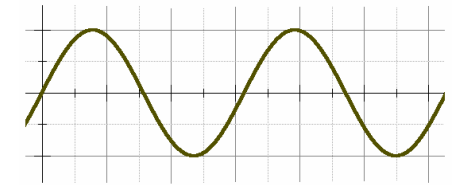

Figura 5. Representação de uma onda senoidal. 


\section{Revista TECCEN - Edição Especial - volume 2 - número 1 - março de 2009 - ISSN 1984-0993}

Para a representação do som na senoide, o ponto máximo chamado de crista, corresponde à compressão, sendo o ponto mínimo, chamado de ventre, correspondente a rarefação.

No exemplo do diapasão, é produzida uma freqüência natural, ou seja, a vibração resultante de seu próprio conjunto de freqüências particulares, que juntas formam seu som próprio. A Figura 6 demonstra a representação do som em relação ao movimento vibratório do diapasão.

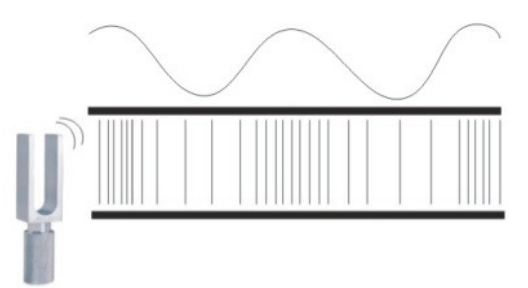

Figura 6. Representação da uma onda senoidal de um som produzido pelo diapasão.

\section{Noções de Cardiologia Aplicada}

\subsection{Ausculta Cardíaca}

Na medicina, a Semiologia está relacionada ao estudo dos sinais e sintomas das doenças

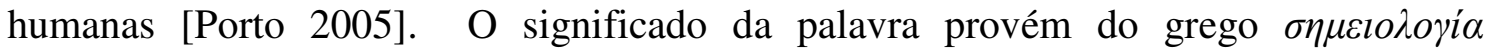
(semeîon, sinal + lógos, tratado, estudo). A Ausculta Cardíaca é uma de suas áreas, onde são estudados os sons e ruídos gerados pelo ciclo cardíaco e seu significado.

Habitualmente, o estetoscópio é utilizado para realizar a ausculta, amplificando os sons corporais. Foi desenvolvido por René Leannex em 1816. É composto por Olivas Auriculares, peças em formato anatômico, que se encaixam no ouvido do examinador; tubo de condução, tubos que permitem a transmissão do som; campânula, peça de contato com o corpo do paciente ou examinado, mais apropriado para percepção de sons graves; e diafragma, peça de contato com o corpo do examinado, mais apropriado para percepção de sons agudos.

\subsection{Sons Cardíacos}

Os sons cardíacos normais (Primeira Bulha e Segunda Bulha) são produzidos pelo movimento das válvulas cardíacas, que se fecham de forma abrupta para impedir a regurgitação do sangue (Figura 7).

Na Figura 8 podem-se observar as quatro áreas auscultatórias existentes: (1) Aórtico, (2) Pulmonar, (3) Tricúspide e (4) Mitral. O especialista ao realizar a ausculta cardíaca, ouve e examina cuidadosamente cada um desses pontos.

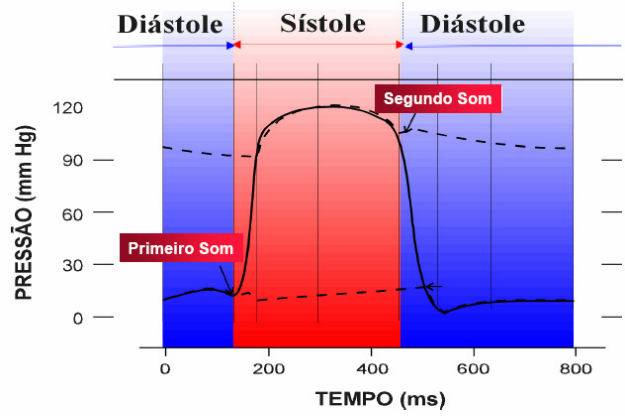

Figura 7. Sons do ciclo cardíaco.

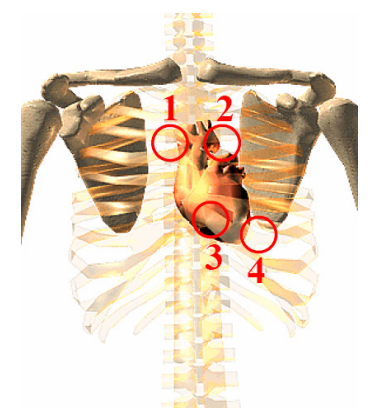

Figura 8. Áreas auscultatórias. 


\section{Revista TECCEN - Edição Especial - volume 2 - número 1 - março de 2009 - ISSN 1984-0993}

O primeiro som cardíaco localiza-se no início da fase de contração (sístole). É de alta frequiência e audível em todos os focos auscultatórios. Ocorre quando o sangue presente nos átrios passa para os ventrículos, neste instante as válvulas, mitral e tricúspide, se fecham evitando a regurgitação do sangue para os átrios.

O segundo som cardíaco é localizado no fim da fase de contração (sístole). É um som também de alta freqüência. Ocorre quando o sangue presente nos ventrículos é expulso através das artérias aórtica e pulmonar, neste instante as válvulas, aórtica e pulmonar, se fecham evitando que o sangue volte para os ventrículos (Figura 9).

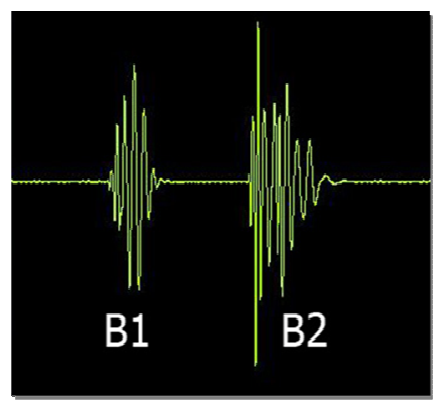

Figura 9. Primeira e Segunda Bulha (B1 e B2).

\section{Projeto CARDIOS}

CARDIOS é um software educativo desenvolvido para auxiliar as aulas práticas de ausculta cardiovascular. Consiste em uma interface gráfica amigável que possibilita ao professor e aos alunos ouvirem o som do batimento cardíaco e simultaneamente ver os gráficos gerados por este som. Através deste gráfico é possível identificar diversas doenças cardíacas, sendo assim de grande utilidade para se formar um diagnóstico inicial e decidir qual o melhor exame ou tratamento a ser seguido pelo paciente.

O software apresenta detalhes sobre os aspectos fisiológicos do coração, disponibilizando ao usuário uma parte bastante didática, contendo sons, gráficos e textos explicativos sobre os sons cardíacos. O mesmo ocorre para os aspectos patológicos, onde traz um breve resumo das estenoses e insuficiências cardíacas com seus respectivos sons (Figura 10).

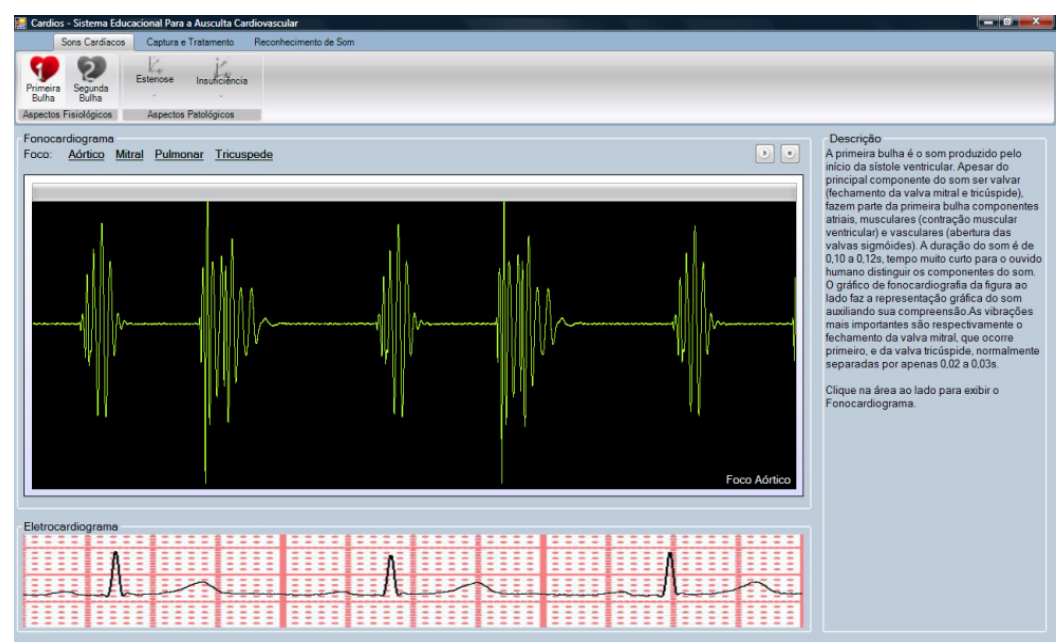

Figura 10. Interface do CARDIOS (Opção "Primeira Bulha" selecionada). 


\section{Revista TECCEN - Edição Especial - volume 2 - número 1 - março de 2009 - ISSN 1984-0993}

O CARDIOS é capaz de ler qualquer arquivo de som no formato wave e plotar o gráfico gerado pela amplitude deste som no domínio do tempo. O usuário também tem a opção de ouvir este som a qualquer momento.

Utilizando um aparelho de captação de pulso cardíaco digital específico, por exemplo, um estetoscópio digital, é possível visualizar o batimento cardíaco em tempo real no domínio da freqüência (Figura 11).

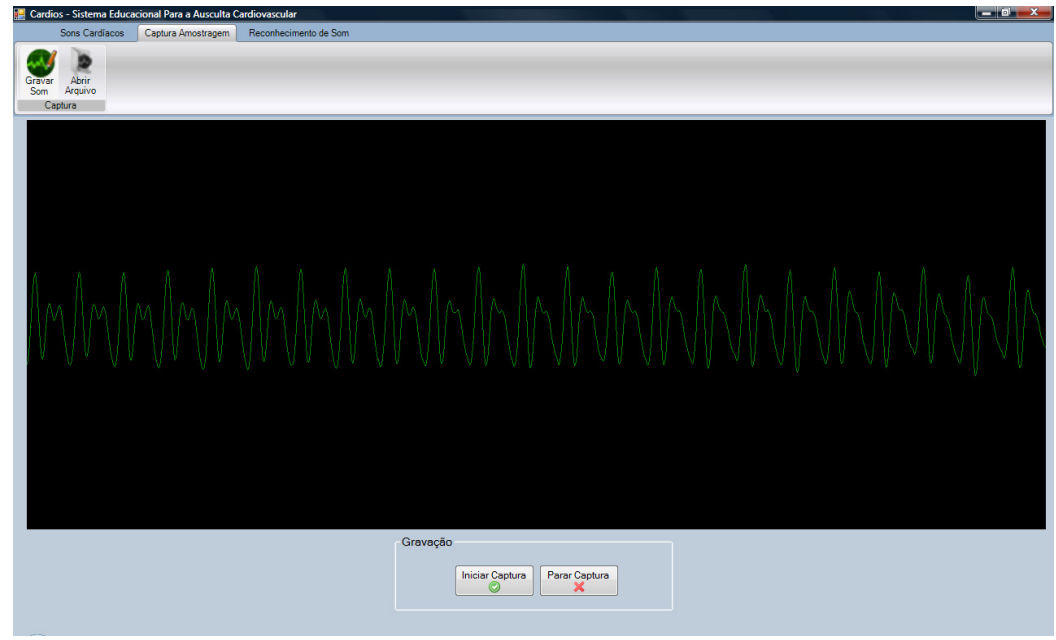

Figura 11. Selecionada a opção "Gravar som".

Além das funcionalidades descritas, o CARDIOS é capaz de reconhecer se um batimento cardíaco é normal ou não, apresentando a resposta possível ao professor especialista e alunos (Figura 12). Para isso utiliza-se uma técnica da análise de máximos a mínimos. Foram reunidas 15 amostras de batimentos normais e anormais, apresentando ao software três vezes cada um, onde se constatou que o número de máximos e mínimos de uma amostra de batimento cardíaco na mesma amplitude e tempo de gravação, possui aproximadamente 100 números a menos que qualquer batimento cardíaco que apresenta alguma anormalidade. Com isso, apresentando-se uma amostra de som no formado wave realiza-se a classificação do som, conforme as especificações citadas. Após a abertura do arquivo, clique no botão "Classificar", o software irá mostrar o número de máximos e mínimos, juntamente com a classificação.

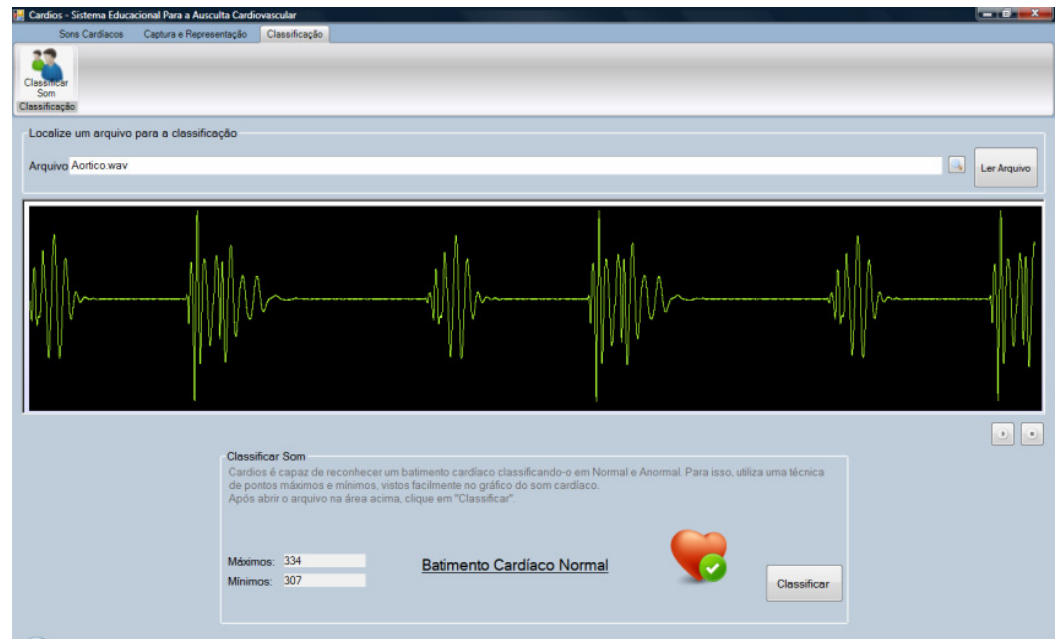

Figura 12. Som cardíaco normal identificado. 


\section{Revista TECCEN - Edição Especial - volume 2 - número 1 - março de 2009 - ISSN 1984-0993}

\subsection{Redes Neurais Artificiais}

Redes Neurais Artificiais (RNA) são técnicas computacionais que buscam, através de modelos matemáticos, uma representação do cérebro humano para a resolução de problemas. Após o treinamento, espera-se da rede, com pesos ajustados, o reconhecimento de padrões, classificação, entre outras diversas aplicações. Basicamente, existem dois tipos de treinamento:

- Treinamento supervisionado - Neste método uma sequiência de padrões, cada qual com um alvo de saída associada ("professor"), são apresentados a RNA. Os pesos são ajustados de acordo com o algoritmo de treinamento que visa aproximá-los ao máximo dos padrões de entrada.

- Treinamento não-supervisionado - Neste método uma seqüência de padrões, os quais não possuem alvo de saída associada ("professor"), são apresentados a RNA. Os pesos são ajustados de acordo com o algoritmo de treinamento. Neste caso, a RNA ajusta os pesos de tal maneira que os padrões de entrada similares são agrupados em uma mesma unidade de saída (clusters).

Uma RNA do tipo Multilayer Perceptron (MLP) é constituída por um conjunto de nós de entrada, uma ou mais camadas escondidas e uma camada de saída. Com exceção da camada de entrada, todas as outras camadas são constituídas por neurônios (Figura 3).

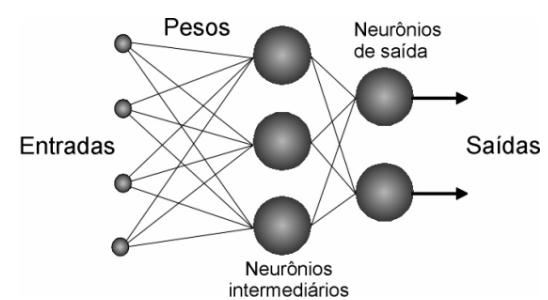

Figura 13 - Arquitetura de uma Rede Neural Artificial.

Cada neurônio baseia-se no modelo proposto por McCulloch e Pitts (Figura 14), que compreende [Mendes 2008]:

- Estímulos de entrada $(\mathrm{X})$ - Cujos componentes são representados pelo vetor $\mathrm{X}$;

- Ligações sinápticas (W) - Cujos componentes são representados pelo vetor $\mathrm{W}$;

- Saída (Y) - Cujos componentes são representados pelo vetor Y, produzido segundo o valor de ativação alcançado pelo neurônio.

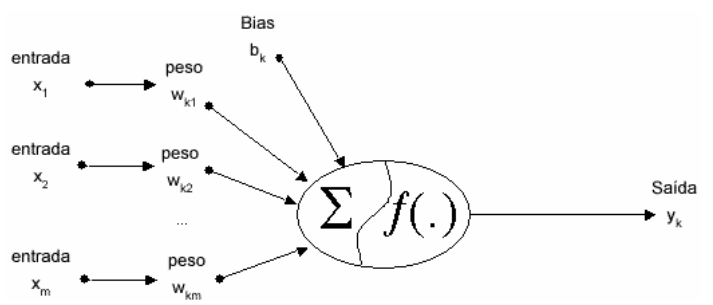

Figura 14 - Modelo de um Neurônio Artificial.

A saída do neurônio é definida pelo valor de ativação, sendo calculado da seguinte forma: $v_{j}=\sum_{i=1}^{m} w_{j i} x_{i}+b$ 


\section{Revista TECCEN - Edição Especial - volume 2 - número 1 - março de 2009 - ISSN 1984-0993}

Onde: v é o valor de ativação do neurônio j; w são os pesos das conexões do neurônio j; $x$ é o valor de cada um dos m estímulos que chegam ao neurônio j, e b é o valor do bias (variável auxiliar com a finalidade de aumentar ou diminuir a influência das entradas) que será somado ao resultado da combinação linear para compor o valor de ativação.

\subsection{Tratamento e representação numérica do som}

Conforme visto, para a representação do som num ambiente computacional torna-se necessário a quantização do som, ou seja, um registro numérico. Para isso, foi utilizado uma função do software MatLab [Matlab 2008] chamada wavread, onde retorna em Y os respectivos valores da amplitude. Após extrair estes números, é possível utilizá-los para a plotagem de um gráfico do som no domínio do tempo, por exemplo.

Porém, para o treinamento da rede neural, tornava-se ineficaz, pois a função retorna valores segundo a configuração da taxa de amostragem da placa de som, aproximadamente 20.000 valores para um som de apenas 5 segundos. É necessário um tratamento na base de dados, ou seja, uma forma de representação do som, em que não se perca informação importante, tornando-se então um problema de sistemas de equações lineares.

Utiliza-se a Eliminação Gaussiana para a solução deste problema, pois ela é capaz de reduzir a base com $\mathrm{n}$ valores, em um número g escolhido, tal que g é o grau do polinômio. Antes da aplicação da Eliminação Gaussiana, é aplicada na base de dados uma técnica matemática chamada de Método dos Mínimos Quadrados (MMQ).

\subsubsection{Método dos Mínimos Quadrados}

Dados os pontos $\left(\mathrm{x}_{1}, \mathrm{y}_{1}\right),\left(\mathrm{x}_{2}, \mathrm{y}_{2}\right), \ldots,\left(\mathrm{x}_{\mathrm{n}}, \mathrm{x}_{\mathrm{n}}\right)$ (obtidos com a função wavread), o resultado que se espera é o polinômio que melhor aproxima (interpola) os $n$ pontos no plano. $\mathrm{O}$ critério significa a menor soma dos quadrados dos desvios.

De forma geral, o Método dos Mínimos Quadrados MMQ pode ser descrito conforme a figura a seguir, onde a matriz simétrica representa os somatórios dos valores do eixo $\mathrm{X}$ (matriz à esquerda) e $\mathrm{Y}$ (matriz à direita), elevados a uma potência g. Esta potência é o grau do polinômio que irá representar a curva. A variável k representa um índice numérico (equação 1).

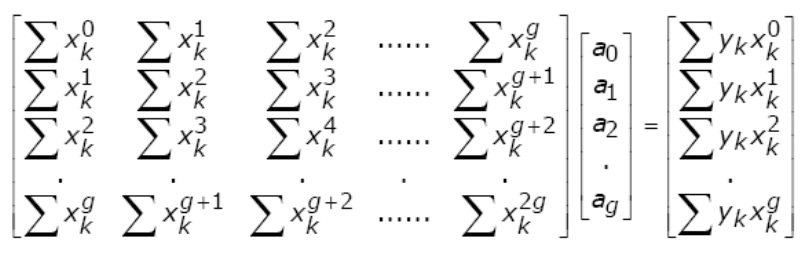

\subsubsection{Eliminação Gaussiana}

Após os valores dos somatórios de x e y obtidos com o MMQ, é fornecido como entrada para uma função Gauss (eliminação gaussiana), onde a saída serão os coeficientes $\mathrm{a}_{0}, \mathrm{a}_{1}$, $\mathrm{a}_{2}, \ldots \mathrm{a}_{\mathrm{g}}$ (tal que, g é o grau do polinômio). Estes coeficientes são os valores numéricos que melhor identificam uma curva, quando informados no polinômio de grau $\mathrm{g}$, escolhida anteriormente, no MMQ.

Portanto, não importa o tamanho da base gerada pela função wavread, utilizado as técnicas MMQ e Eliminação Gaussiana, a base é reduzida a um número definido. 


\section{Revista TECCEN - Edição Especial - volume 2 - número 1 - março de 2009 - ISSN 1984-0993}

Resta apenas, analisar a curva, verificar o número de máximos e mínimos e definir o grau do polinômio.

\section{Conclusões}

Ao definir a proposta do projeto, era inerente a multidisciplinaridade. A semiologia, com a evolução natural de longos anos, apresenta um grande avanço em técnicas para o ensino da ausculta cardiovascular. Por outro lado, com novas tecnologias computacionais surgindo diariamente, a sinergia entre as duas áreas, Ciência da Computação e Cardiologia tornam-se inovação e eficiência em construção de soluções tecnológicas. Observa-se isso fortemente presente em laboratórios, exames diagnósticos, hospitais, entre outros. Para a área do ensino, especificamente, da ausculta cardiovascular, tal sinergia não deixa de estar presente, porém, a presença não é tão expressiva. A Ciência da Computação pode desenvolver softwares que, além de facilitar, ampliam as ferramentas para o docente aplicar no ensino. Com o projeto CARDIOS, buscou-se tal sinergia, onde a solução desenvolvida promove ao aluno a prática, em ouvir e reconhecer a representação do som cardíaco. Utilizando equipamentos de hardware específico, o software é capaz de exibir o gráfico do som auscultado, facilitando assim, a compreensão por parte do aluno. Na pesquisa científica realizada, utilizando técnicas de sistemas lineares, Método dos Mínimos Quadrados e Eliminação Gaussiana, obteve-se um resultado eficiente quanto à representação do som, onde se aplicando a uma rede neural, é possível a identificação da doença cardiovascular.

Os resultados possibilitam o desenvolvimento de trabalhos futuros. Utilizando a técnica de representação do som apresentada, estudos quanto à identificação de som em outros contextos podem ser efetuadas. A conclusão do desenvolvimento do protótipo possibilita a implantação do software no Laboratório de Habilidades do UNIFESO, promovendo uma aplicação prática dentro da universidade. Do ponto de vista da sinergia, apresenta-se a proposta quanto à pesquisa em soluções que podem ser construídas para o ensino em medicina, os avanços da Ciência da Computação são de fato imponentes dentro da própria área. Porém, a aplicação deste avanço para a prática da docência médica é ainda embrionária, descerrando um vasto caminho para o desenvolvimento de pesquisas científicas e soluções computacionais.

\section{Referências Bibliográficas}

3B, Brasil Scientific. Simulador de Ausculta com SmartScope, 2008. Disponível em: http://www.3bscientific.com.br/shop/brasil/exame-medico-e-autoexame/simuladorde-ausculta-com-smartscope. Acesso em: 02 de dezembro de 2008.

Blaufuss. Heart Sounds and Cardiac Arrhithmias, 2008. Disponível em: http://www.blaufuss.org/. Acesso em: 02 de dez. de 2008.

CADI. An Intelligent, Multimedia Tutor for Cardiac Auscultation, 2008. Disponível em: http://www.aaai.org/Library/AAAI/1996/aaai96-238.php. Acesso em: 02 de dezembro de 2008.

Dias, Robson. Curso de Teoria Musical, 2000. Disponível em: http://www.atelierdavovo.com/teoria/teoria/aula01/. Acesso em: 17 de julho de 2008.

Fourier, Jean Baptiste Joseph, 2008. Disponível em: http://www.stetson.edu/ efriedma/periodictable/html/Fe.html. Acesso em: 15 de dezembro de 2008. 


\section{Revista TECCEN - Edição Especial - volume 2 - número 1 - março de 2009 - ISSN 1984-0993}

Hewitt, Paul G. Física Conceitual. 9. ed. Porto Alegre: Editora Bookman, 2002. Matlab. Matlab Trial Software, 2008. Disponível em: http://www.mathworks.com/ products/matlab/tryit.html. Acesso em 20 de novembro de 2008.

Mendes, Daniele Quintela. O modelo do Neurônio Artificial - Laboratório Nacional de Computação Científica. 2008. Disponível em: http://www.lncc.br/ labinfo/ tutorialRN/. Acesso em: 10 de julho de 2008.

Neto, Wilson Castello Branco. Sistemas de Reconhecimento de Som para Afinação de Instrumentos. Dissertação de Mestrado. Universidade Federal de Santa Catarina em dezembro de 2007.

PEC. Programa Educacional em Cardiologia, 2008. Disponível em: http://www.virtual.unifesp.br/unifesp/cardio. Acesso em: 02 de dezembro de 2008.

Porto, Celmo Celeno. Semiologia Médica. 5a. ed. São Paulo: Editora Guanabara Koogan, 2005.

Sommers, D., McNeill, P. Turchin, B. Physical Characteristics, 1996. Disponível em: http://library.thinkquest.org/2662/TQ1996/characteristics.html. Acesso em 17 de julho de 2008. 